\title{
Regulation of Mucin 1 and multidrug resistance protein 1 by honokiol enhances the efficacy of doxorubicin-mediated growth suppression in mammary carcinoma cells
}

\author{
PADMAMALINI THULASIRAMAN and ANDREA BUTTS JOHNSON \\ Department of Biomedical Sciences, College of Allied Health, University of South Alabama, Mobile, AL 36688, USA
}

Received February 26, 2016; Accepted April 6, 2016

DOI: $10.3892 /$ ijo.2016.3534

\begin{abstract}
Understanding the link between chemoresistance and cancer progression may identify future targeted therapy for breast cancer. One of the mechanisms by which chemoresistance is attained in cancer cells is mediated through the expression of multidrug resistance proteins (MRPs). Acquiring drug resistance has been correlated to the emergence of metastasis, accounting for the progression of the disease. One of the diagnostic markers of metastatic progression is the overexpression of a transmembrane protein called Mucin 1 (MUC1) which has been implicated in reduced survival rate. The objective of this study was to understand the relationship between MUC1 and MRP1 using natural phenolic compound isolated from Magnolia grandiflora, honokiol, in mammary carcinoma cells. We provide evidence that honokiol suppresses the expression level of MUC1 and MRP1 in mammary carcinoma cells. In a time-dependent manner, honokiol-mediated reduction of MUC1 is followed by a reduction of MRP1 expression in the breast cancer cells. Additionally, silencing MUC1 suppresses the expression level of MRP1 and enhances the efficacy of doxorubicin, an MRP1 substrate. Taken together, these findings suggest MUC1 regulates the expression of MRP1 and provides a direct link between cancer progression and chemoresistance in mammary carcinoma cells.
\end{abstract}

\section{Introduction}

Breast cancer is the most common type of cancer in women, with over one million cases diagnosed worldwide $(1,2)$. Despite

Correspondence to: Dr Padmamalini Thulasiraman, Department of Biomedical Sciences, College of Allied Health, University of South Alabama, 5721 USA Drive North, Mobile, AL 36688, USA E-mail: pthulasiraman@southalabama.edu

Abbreviations: MRP, multidrug resistance protein; MUC1, Mucin 1; MDR, multidrug resistance; ABC, ATP-binding cassette; P-gp, P-glycoprotein; DOX, doxorubicin; MTT, (3-(4,5-dimethylthiazol2-yl)-2,5-diphenyl tetrazolium bromide; DMSO, dimethyl sulfoxide; qRT-PCR, quantitative real-time polymerase chain reaction; GAPDH, glyceraldehyde-3-phosphate dehydrogenase

Key words: Mucin 1, multidrug resistance protein 1, honokiol, doxorubicin, drug resistance, breast cancer improvements in the development of chemotherapeutic drugs for breast cancer treatment, cancer related death rates continue to rise. Over time patients develop multidrug resistance (MDR) to chemotherapeutic drugs and this is a major factor in the failure of many forms of therapy, which can ultimately lead to tumor metastasis, affecting the quality of life of survivors and contributing to the mortality rate $(3,4)$. Thus, it is of significant value to investigate the mechanism and pathways linked to drug resistance and metastasis in order to improve therapeutic treatments.

The development of resistance to chemotherapeutic agents occurs frequently in breast cancer patients and is a major factor for poor prognosis, mortality and morbidity in these patients (5). Among the strategies by which cancer cells acquire drug resistance is via the overexpression of ATP-binding cassette (ABC) transporters (6) which function as an energy-dependent efflux pump. The ABC transporters family include the P-glycoprotein (P-gp)/MDR belonging to the ABCB family (7). Included in the ABC superfamily are the multidrug resistance-protein (MRP) family of transporter proteins encoded by ABCC1-6, 10-13, the ATP-gated chloride channel, CFTR (ABCC7) and the ATP-dependent sulfonylurea receptors, SUR (ABCC8, 9) (6). Of these, MRP1/ABCC1 is designated as a negative prognostic marker for early stage breast cancer, with reports linking a strong correlation of its expression to relapse and overall survival in several cancers (8-11). Although MRP1 is expressed in normal tissues, several studies have demonstrated overexpression of MRP1 in multiple solid tumors including breast, lung and prostate $(6,12)$. Overexpression of MRP1 in breast cancer lymph nodes has been associated to the metastatic potential of the disease (13). Expression pattern of MRP1 makes this an optimal candidate for use as a marker for prediction of chemoresistance. Although the structure and function of ABC transporters have been explored in detail, developing effective agents against these transporters have not been translated into a clinical target (14).

Controlling cancer at the initial stage is vital in managing the disease. Tumor progression and metastasis within the body results in chemoresistance or an increase in chemotherapeutic dosage which ultimately causes cardiac toxicity (15). Hence, conventional therapeutic options have not been successful in halting the progression of the disease, and thus understanding the role of key proteins in the dissemination and metastasis of tumor cells will be essential in identifying effective and 
innovative drug alternative to treat the disease at its initial or later stages. One of the diagnostic markers of metastatic progression is the overexpression of a transmembrane protein called Mucin 1 (MUC1) which has been implicated in reduced survival rate. Among the many functions associated with mucins, MUC1 is involved in cell growth, cell adhesion, motility and cell survival $(16,17)$. MUC1 has also been implicated in chemoresistance and studies have shown that cancers overexpressing MUC1 are unresponsive to therapeutic chemotoxic drugs (18-20). A link between metastasis and chemoresistance has been observed in pancreatic cancer cells, whereby MUC1 has been shown to upregulate MRP1, lowering sensitivity to chemotherapeutic agents (18). This study from Nath et al (18) provides a mechanistic insight on the correlation between chemoresistance and metastasis in pancreatic cells. However, little is known on the relationship between MUC1 and MRP1 in mammary carcinoma cells. Targeting both MRP1 and MUC1 may provide an opportunity to intervene with drug resistance, and ultimately reduce the migration of cancer cells to other parts of the body, while augmenting the efficacy of chemotherapeutic drugs such as doxorubicin (DOX) against breast cancer cells.

Due to the cardiac toxicity associated with chemotherapeutic drugs such as DOX (15), various approaches to enhance chemoresponse in cancer models have been explored, including combining standard chemotherapy agents with natural products $(21,22)$. Honokiol, isolated from the bark of the magnolia tree, has been found to have anti-oxidant (23), anti-inflammatory (24) and anticancer properties $(25,26)$, promoting its potential for targeting various diseases, including cancer, arthritis, and diabetes (25-29). In addition to the multifaceted effects of honokiol, it has improved the actions of conventional chemotherapies to promote growth suppression or overcome drug resistance in a variety of preclinical models of human cancer, including skin cancer (30), prostate cancer (31) and multiple myeloma (32).

The study was aimed to investigate the relationship between the process of chemoresistance and cancer progression in mammary carcinoma cells by characterizing the effect of honokiol on MRP1 and MUC1 gene expression, two proteins directly involved in these activities. In this study, we demonstrate that honokiol suppresses the expression of MUC1 and MRP1 in mammary carcinoma cells. Based on these data, we provide mechanistic evidence that honokiol enhances the efficacy of DOX by regulating the expression of MUC1, which directly downregulates MRP1. Thus, understanding the mechanism by which honokiol promotes its anti-carcinogenic effects and prevents drug resistance may provide mechanistic insights into the underlying antitumor effects of honokiol, alone or in combination with chemotherapeutic agents, in breast cancer.

\section{Materials and methods}

Reagents. Antibodies against MUC1 were obtained from Santa Cruz Biotechnology (Santa Cruz, CA, USA) and $\beta$-tubulin was purchased from Sigma Aldrich Co (St. Louis, MO, USA). Antibodies for MRP1 were obtained from Abcam (Cambridge, MA, USA). Anti-mouse and anti-rabbit immunoglobulin horseradish peroxidase-conjugated antibodies were from Bio-Rad (Hercules, CA, USA), and anti-goat immunoglobulin was from Santa Cruz. Honokiol was obtained from LKT Laboratories (St. Paul, MN, USA) and DOX was purchased from Sigma. MTT reagent (3-(4,5-dimethylthiazol2-yl)-2,5-diphenyl tetrazolium bromide) was purchased from Sigma. MUC1 and control siRNA were purchased from Santa Cruz Biotechnology.

Cell lines. MCF-7, MCF10A and MDA-MB-231 cells were maintained in Dulbecco's modified Eagle's medium (DMEM) supplemented with $10 \%$ fetal bovine serum (FBS) with antibiotics-antimycotics. DMEM was obtained from Life Technologies (Grand Island, NY, USA). FBS and antibioticsantimycotics were purchased from Atlanta Biologicals (Flowery Branch, GA, USA). MCF-7 and MDA-MB-231 cells were a kind gift of Dr Ming Tan (Mitchell Cancer Institute, Mobile, AL, USA). MCF10A was purchased from American Type Culture Collection (ATCC, Manassas, VA, USA).

Honokiol and DOX preparation. Honokiol was prepared at a stock concentration of $10 \mathrm{mM}$ in dimethyl sulfoxide (DMSO) and cells were treated at the appropriate concentration, using DMSO as control. DOX was prepared at a stock concentration of $2 \mathrm{mM}$ in water and diluted at the appropriate concentration for the treatment of cells.

Western blot analyses. Cells were cultured in $100-\mathrm{mm}$ plates and treated with honokiol for either 24 or $48 \mathrm{~h}$. DMSO was used as control. Cells were lysed in ice-cold buffer containing $150 \mathrm{mM} \mathrm{NaCl}, 10 \mathrm{mM}$ Tris, $\mathrm{pH}$ 7.2., $0.1 \%$ SDS, $1 \%$ Triton X-100, $1 \%$ deoxycholate, $5 \mathrm{mM}$ EDTA, and $1 \mathrm{mM}$ PMSF. Cells were lysed on ice for $1 \mathrm{~h}$ and protein concentration was determined by the Bradford assay. Cell lysate was resolved by SDS-PAGE and blotted onto a nitrocellulose membrane. The membrane was blocked in $10 \%$ bovine serum albumin in Tris-buffer saline containing $0.05 \%$ tween for $1 \mathrm{~h}$ at room temperature. The membrane was then incubated with primary antibody, MUC1 or MRP1 at a dilution of 1:1,000 overnight at $4^{\circ} \mathrm{C}$. For equal loading, $\beta$-tubulin $(1: 1,000)$ was incubated with the membrane for $1 \mathrm{~h}$ at $4^{\circ} \mathrm{C}$. The antigen-antibody complex was visualized with SuperSignal West Pico Chemiluminescent Substrate (Fisher, Hanover Park, IL, USA).

Quantitative real-time polymerase chain reaction ( $q R T-P C R)$. Cells were treated with honokiol for $48 \mathrm{~h}$, and RNA was extracted using TRIzol (Life Technologies). As described in the high capacity RNA to cDNA kit from Applied Biosystems, $2 \mu \mathrm{g}$ total RNA was reverse transcribed into cDNA. To determine expression of MUC1 and ABCC1, qRT-PCR was carried out by using commercially available Taqman Chemistry and Assay on Demand Probes (Applied Biosystems). Glyceraldehyde-3-phosphate dehydrogenase (GAPDH) was used for normalization. Detection and data analysis were carried out on the ABI Step One Plus Real-Time PCR System. Relative quatity of gene expression was performed using $2^{-\Delta \Delta \mathrm{Ct}}$ method (33).

Cell viability assay. For cell proliferation assays, 5,000 cells of MDA-MB-231 and MCF-7 were seeded in a 96-well plate and allowed to adhere overnight. Cells were then treated with 
A

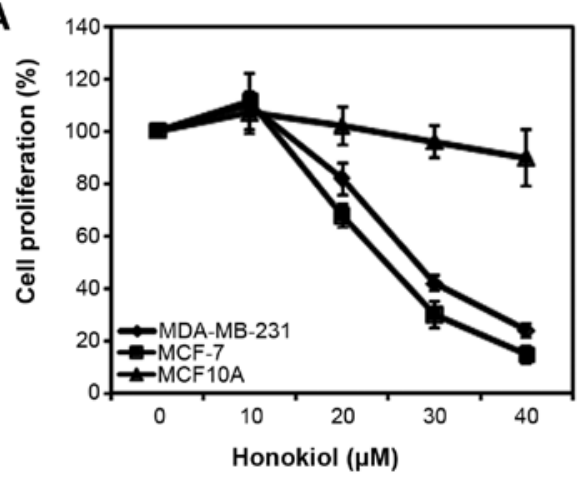

B

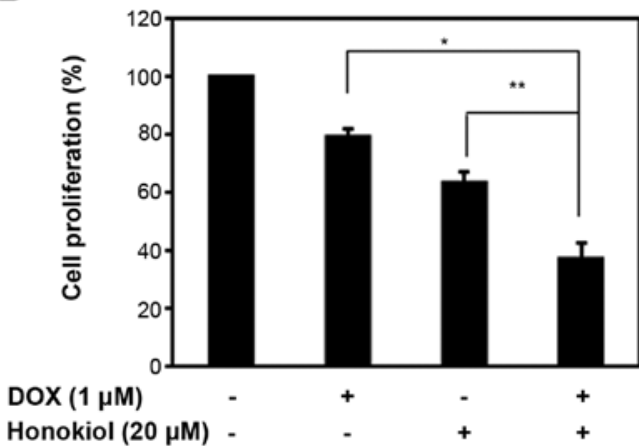

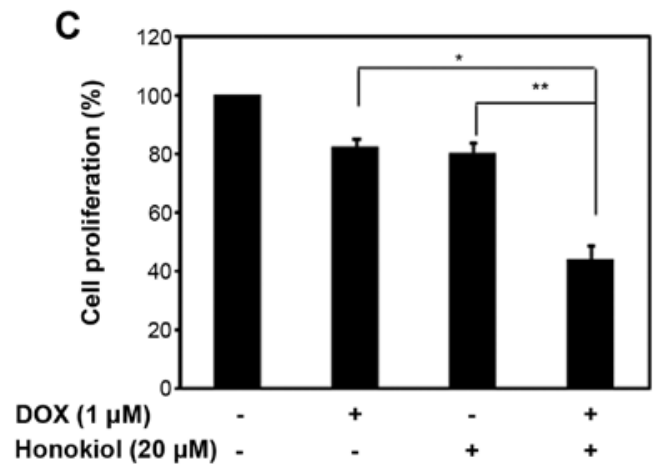

Figure 1. Honokiol enhances the efficacy of DOX in mammary carcinoma cells. (A) MDA-MD-231, MCF-7 and MCF10A cells were plated in 96-well plates, treated with varying dose of honokiol for $48 \mathrm{~h}$. The control was DMSO treated according to the concentration of the cells treated with honokiol. The percentage (\%) cell proliferation for each of the treatment with honokiol for the designated concentration was calculated with respect to the treatment with DMSO for the corresponding dose. Data are mean of $\pm \mathrm{SE}(\mathrm{n}=3)$. (B) MCF-7 cells were plated in 96-well plates, and treated with $1 \mu \mathrm{M}$ DOX in the presence or absence of $20 \mu \mathrm{M}$ honokiol for $48 \mathrm{~h}$. The percentage of cell proliferation for each of the treatment (DOX, honokiol or both) was calculated relative to their solvent, water, DMSO or the combination, respectively. The controls were set at $100 \%$. Data are mean of $\pm \mathrm{SE}(\mathrm{n}=3)$. ${ }^{*} \mathrm{p}=0.01$; ${ }^{* *} \mathrm{p}=0.008$. (C) MDA-MD-231 cells were plated in 96-well plates, and treated with $1 \mu \mathrm{M}$ DOX in the presence or absence of $20 \mu \mathrm{M}$ honokiol for $48 \mathrm{~h}$. The percentage (\%) cell proliferation for each of the treatment (DOX, honokiol or both) was calculated relative to their solvent, water, DMSO or the combination, respectively. The controls were set at $100 \%$. Data are mean of $\pm \mathrm{SE}(\mathrm{n}=3) .{ }^{*} \mathrm{p}=0.02 ;{ }^{* *} \mathrm{p}=0.002$.

honokiol in the presence or absence of DOX for $48 \mathrm{~h}$. Controls were treated with or without DMSO depending on the drug treatment. After $48 \mathrm{~h}, 5 \mu \mathrm{g} / \mathrm{ml}$ MTT reagent was added directly to the cells for $3 \mathrm{~h}$, or until crystals formed. The media was carefully removed from the plate, leaving the cells intact and the cells were then resuspended in $150 \mu 1$ of $0.04 \mathrm{M} \mathrm{HCl}$ in isopropanol. Absorbance was read at $570 \mathrm{~nm}$ to determine cell proliferation.

Cell transfection. MCF-7 and MDA-MB-231 cells were transfected according to the protocol provided by Invitrogen (Grand Island, NY, USA). Briefly, 180 pmol of control or MUC1 siRNA was mixed with 2 ml Gibco Opti-MEM ${ }^{\circledR}$ I medium without serum by Life Technologies in a $100-\mathrm{mm}$ plate. Lipofectamine ${ }^{\mathrm{TM}}$ RNAiMAX (25 $\mu$ l) was added to the diluted RNAi mix and left for $20 \mathrm{~min}$ at room temperature. Cultured MCF-7 or MDA-MB-231 cells were subdivided and $2 \times 10^{6}$ cells were diluted in the media. Cells were added to the plates containing the RNAi duplex/Lipofectamine ${ }^{\mathrm{TM}}$ mixture labeled with control or MUC1 siRNA. The cells were incubated for $48 \mathrm{~h}$ at $37^{\circ} \mathrm{C}$ in a $\mathrm{CO}_{2}$ incubator. After $48 \mathrm{~h}$, cells were lysed, protein was extracted, quantitated and protein extract was loaded onto a gel for SDS-PAGE. The blot was probed for MUC1 with MUC1 antibody to assay knockdown of the protein, and using the same extract, MRP1 protein expression was probed with MRP1 antibody.
Trypan blue exclusion assay. As described above, MCF-7 and MDA-MB-231 cells were transfected with control or MUC1 siRNA overnight, followed by treatment with $1 \mu \mathrm{M}$ DOX for $48 \mathrm{~h}$. After $48 \mathrm{~h}$, cells were trypsinized, collected and counted using trypan blue. Live cells are presented as number of cells $/ \mathrm{ml}$.

Statistical analysis. Statistical significance of differences between treatments was determined using two tailed Student's $\mathrm{t}$-test and $\mathrm{p}$-values were noted. Differences between groups were considered statistically significant at $\mathrm{p}<0.05$.

\section{Results}

Honokiol enhances the efficacy of DOX in mammary carcinoma cells. One of the advantages of honokiol is its lack of toxicity in non-tumorigenic cells, promoting its use with conventional chemotherapeutic agents (34). To compare the effects of honokiol on mammary carcinoma cells (MCF-7 and MDA-MB-231) with normal human mammary epithelial cells, we treated the cells with varying concentrations of honokiol. As observed previously $(35,36)$, honokiol had moderate toxicity with a $50 \%$ decrease in cell proliferation at 25 and $28 \mu \mathrm{M}$ honokiol in MCF-7 and MDA-MB-231 cells, respectively, while MCF10A were less sensitive to the antiproliferative effects of honokiol (Fig. 1A). 
A

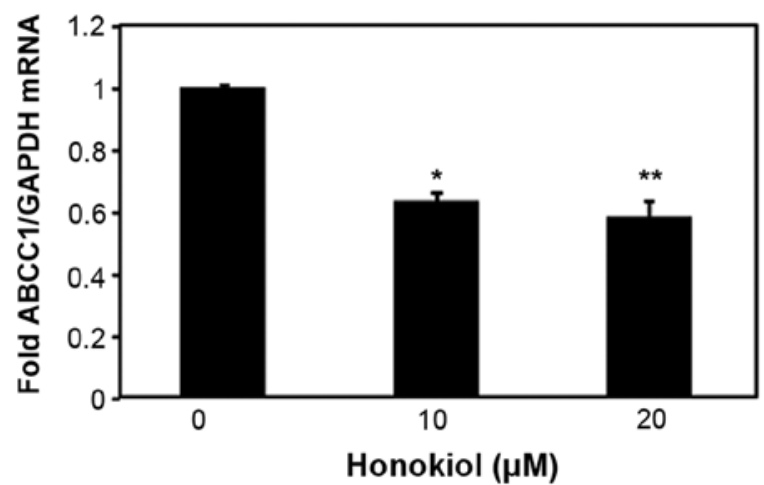

C

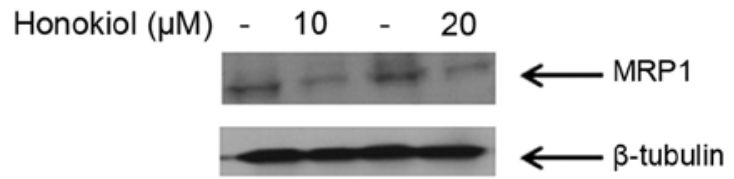

$B$

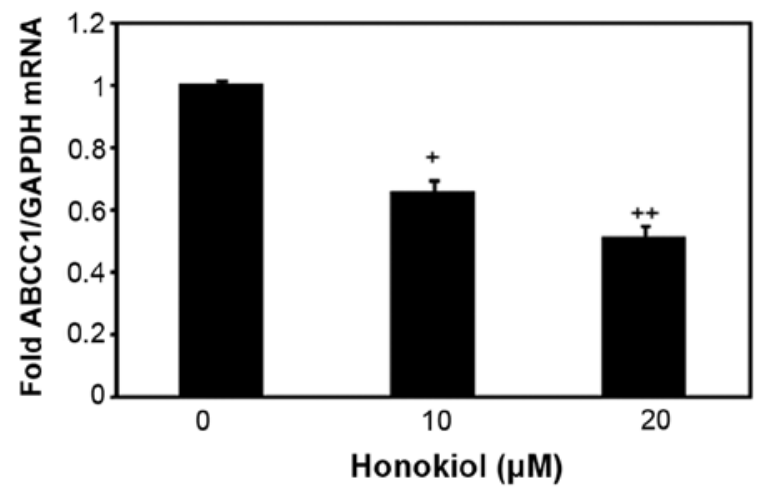

D

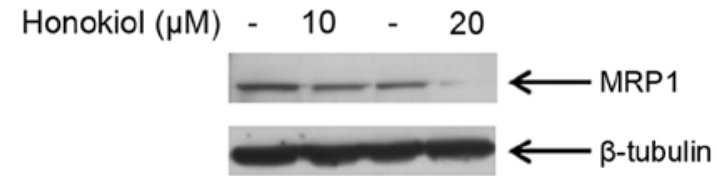

Figure 2. Honokiol suppresses the expression level of ABBC1/MRP1 in mammary carcinoma cells. Total RNA was collected from MCF-7 cells (A) and MDA-MB-231 (B) cells treated with 10 or $20 \mu \mathrm{M}$ honokiol for $48 \mathrm{~h}$ (DMSO was used for the control). Expression level of ABCC1 mRNA in MCF-7 cells (A) and MDA-MB-231 cells (B) were analyzed by qRT-PCR. GAPDH was used for normalization. Data are mean of \pm SE ( $\mathrm{n}=3$ ). * $\mathrm{p}=0.0006 \mathrm{versus}$ control treatment; ${ }^{* *} \mathrm{p}=0.016$ versus control treatment; ${ }^{+} \mathrm{p}=0.01$ versus control treatment; ${ }^{++} \mathrm{p}=0.004$ versus control treatment. MCF-7 (C) and MDA-MB-231 (D) cells were treated with 10 or $20 \mu \mathrm{M}$ honokiol for $48 \mathrm{~h}$ (DMSO was used for the control) prior to cell lysis. Cell lysates were resolved with SDS-PAGE and immunoblotted with antibodies recognizing MRP1, and $\beta$-tubulin was used as a loading control.

Previous studies have shown that combining honokiol with chemotherapeutic agents in a variety of cancer cell lines increases the efficacy of chemotherapeutic agents by augmenting cell growth inhibition or inducing apoptosis (30-32,34,35). We evaluated the ability of honokiol to enhance the efficacy of DOX-mediated growth suppression in MCF-7 and MDA-MB-231. Given that $20 \mu \mathrm{M}$ honokiol suppressed mammary carcinoma cell growth by $\sim 33$ and $20 \%$ in MCF-7 and MDA-MB-231 cells, respectively, we treated mammary carcinoma cells with $1 \mu \mathrm{M}$ of DOX with a fixed $20 \mu \mathrm{M}$ concentration of honokiol and analyzed cell proliferation using MTT assay. As shown in Fig. 1B and C, $1 \mu \mathrm{M}$ DOX suppressed MCF-7 and MDA-MB-231 cell growth, respectively. As observed previously (Fig. 1A), honokiol at $20 \mu \mathrm{M}$ reduced cell growth in MCF-7 and MDA-MB-231 cells (Fig. 1B and C). However, the combination of DOX with honokiol further increased the cell growth inhibitory properties of DOX and improved the potency of DOX in MCF-7 and MDA-MB-231 cells (Fig. 1B and C). This indicates that honokiol improves the efficacy of DOX, ultimately reducing the toxic effects of DOX.

Honokiol regulates the expression of $A B C C 1 / M R P 1$ in mammary carcinoma cells. DOX is a substrate of MRP1 (37). To investigate whether the enhanced efficacy of DOX in mammary carcinoma cells (MCF-7 and MDA-MB-231) treated with honokiol was likely due to the associated changes of $\mathrm{ABCC1}$ expression, we sought to assess the effect of honokiol on $\mathrm{ABCC} 1 \mathrm{mRNA}$ and protein expression in the non-metastatic MCF-7 cells and the highly aggressive MDA-MB-231 cells. To determine whether honokiol regulates the expression of $\mathrm{ABCC} 1$ in these mammary carcinoma cells, we treated MCF-7 and MDA-MB-231 mammary carcinoma cells with 10 and $20 \mu \mathrm{M}$ honokiol for $48 \mathrm{~h}$, and the levels of
ABCC1 mRNA and protein were determined by qRT-PCR and western blotting, respectively. As shown in Fig. 2A, 10 and $20 \mu \mathrm{M}$ honokiol equally suppressed ABCC1 mRNA levels in MCF-7 cells, without a dose response. Similarly, both 10 and $20 \mu \mathrm{M}$ honokiol reduced $\mathrm{ABCC} 1 \mathrm{mRNA}$ expression in MDA-MB-231 cells by $\sim 40$ and $60 \%$, respectively (Fig. 2B). The levels of the respective protein expression of $\mathrm{ABCC} 1$, MRP1 was also analyzed in these cells and consistent with ABCC1 mRNA expression in MCF-7 cells, 10 and $20 \mu \mathrm{M}$ of honokiol reduced MRP1 protein expression in MCF-7 cells (Fig. 2C). To determine whether the inhibitory effects of honokiol on ABCC1 mRNA expression in MDA-MB-231 cells resulted in the suppression of MRP1 protein expression in MDA-MB-231 cells, western blotting was conducted. As shown in Fig. 2D, $20 \mu \mathrm{M}$ honokiol suppressed MRP1 protein expression in MDA-MB-231 cells, while $10 \mu \mathrm{M}$ honokiol had a moderate effect. These results indicate that honokiol suppresses ABCC1 mRNA and the expression of its respective protein, MRP1 in two different breast cancer cell lines, suggesting that the regulation of MRP1 by honokiol is a global effect among mammary carcinoma cells, emphasizing the importance of using honokiol to target drug resistance gene MRP1 in breast cancer.

MUC1 is regulated by honokiol in mammary carcinoma cells. Several studies have suggested the role of MUC1 in conferring drug resistance in cancer cells (18-20), while a study in pancreatic cancer cells specifically demonstrated regulation of MRP1 by MUC1 (18). In order to determine whether honokiol regulates MUC1 in mammary carcinoma cells, MCF-7 and MDA-MB-231 cells were treated with honokiol (10 and $20 \mu \mathrm{M})$ for $48 \mathrm{~h}$ and MUC1 mRNA expression level was analyzed. As shown in Fig. 3A and B, 10 and $20 \mu \mathrm{M}$ honokiol suppressed MUC1 mRNA expression in both MCF-7 and MDA-MB-231 
A

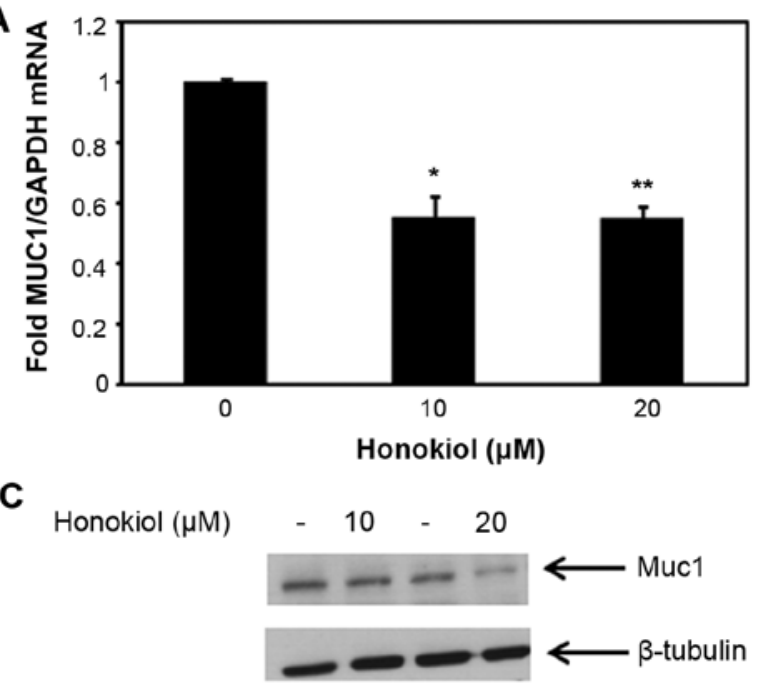

B

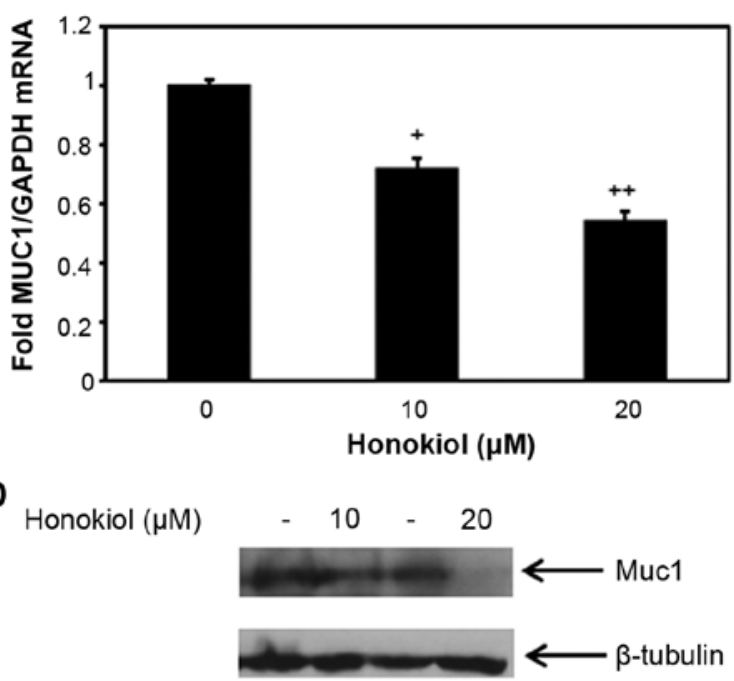

Figure 3. Honokiol suppresses the expression level of MUC1 in mammary carcinoma cells. Total RNA was collected from MCF-7 cells (A) and MDA-MB-231 (B) cells treated with 10 or $20 \mu \mathrm{M}$ honokiol for $48 \mathrm{~h}$ (DMSO was used for the control). Expression level of MUC1 mRNA in MCF-7 cells (A) and MDA-MB-231 cells (B) were analyzed by qRT-PCR. GAPDH was used for normalization. Data are mean of $\pm S E(n=3)$. $" \mathrm{p}=0.02$ versus control treatment; ${ }^{* *} \mathrm{p}=0.006$ versus control treatment; ${ }^{+} \mathrm{p}=0.014$ versus control treatment; ${ }^{++} \mathrm{p}=0.004$ versus control treatment. MCF-7 (C) and MDA-MB-231 (D) cells were treated with 10 or $20 \mu \mathrm{M}$ honokiol for $48 \mathrm{~h}$ (DMSO was used for the control) prior to cell lysis. Cell lysates were resolved with SDS-PAGE and immunoblotted with antibodies recognizing MUC1, and $\beta$-tubulin was used as a loading control.

A

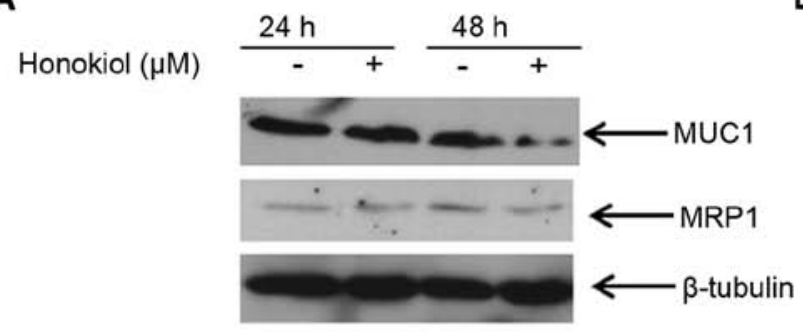

B

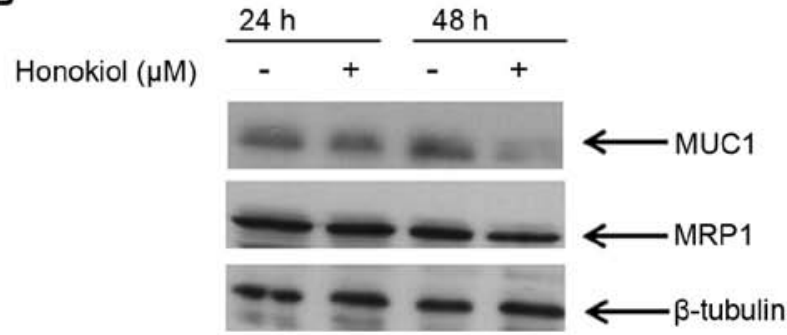

Figure 4. Suppression of MUC1 by honokiol concomitantly reduces MRP1 expression. MCF-7 (A) and MDA-MB-231 (B) cells were treated with $20 \mu \mathrm{M}$ honokiol for 24 and $48 \mathrm{~h}$ (DMSO was used for the control) prior to cell lysis. Cell lysates were resolved with SDS-PAGE and immunoblotted with antibodies recognizing MUC1 and MRP1. $\beta$-tubulin was used as a loading control.

cells (Fig. 3A and B). Concomitantly, we examined the protein expression level of MUC1 in MCF-7 and MDA-MB-231 cells treated with honokiol and observed the downregulation of MUC1 protein in honokiol treated cells (Fig. 3C and D). These results demonstrate that honokiol suppresses MUC1 expression level in MCF-7 and MDA-MB-231 cells, suggesting the regulation of $\mathrm{MUC1}$ by honokiol may be a global effect observed in breast cancer cells.

Relationship between MUC1 and MRPI protein expression in mammary carcinoma cells. To further understand the relationship between MUC1 and MRP1 in mammary carcinoma cells, we specifically examined their protein expression level at 24 and $48 \mathrm{~h}$ of treatment with honokiol. Because significant downregulation of these proteins was observed with $20 \mu \mathrm{M}$ honokiol, we treated MCF-7 and MDA-MB-231 cells with this concentration for 24 and $48 \mathrm{~h}$, and analyzed the expression of these proteins at these two different time-points. Results from western blot analysis showed that $20 \mu \mathrm{M}$ honokiol did not reduce either MUC1 or MRP1 expression at $24 \mathrm{~h}$ in either
MCF-7 or MDA-MB-231 cells (Fig. 4). However, at $48 \mathrm{~h}$, $20 \mu \mathrm{M}$ honokiol reduced MUC1 expression and concomitantly MRP1 protein expression was downregulated in these cell lines (Fig. 4). These data suggest that there may be a correlation between the expression level of MUC1 and MRP1, and in fact reducing MUC1 suppresses MRP1 in mammary carcinoma cells.

Suppression of MUC1 reduces the expression level of MRPI and enhances the efficacy of DOX in mammary carcinoma cells. To investigate whether regulation of MRP1 by honokiol is directly dependent on MUC1 pathway, we silenced MUC1 in mammary carcinoma cells (MCF-7 and MDA-MB-231) with MUC1 siRNA using Lipofectamine RNAimax. For control, we used a non-specific control siRNA. Equal amounts of cell lysates from control and MUC1 knockdown cells were lysed and probed for MUC1 protein expression. As shown in Fig. 5, MUC1 was silenced in both MCF-7 and MDA-MB-231 cells, respectively. Concomitantly, we examined the protein expression level of MRP1 in the control and MUC1 siRNA 
A

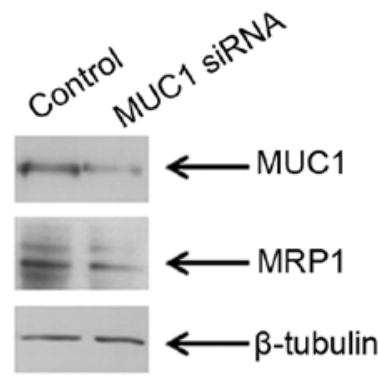

B

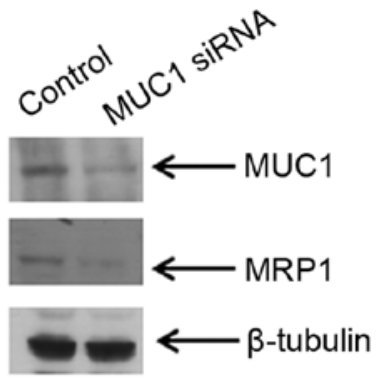

C

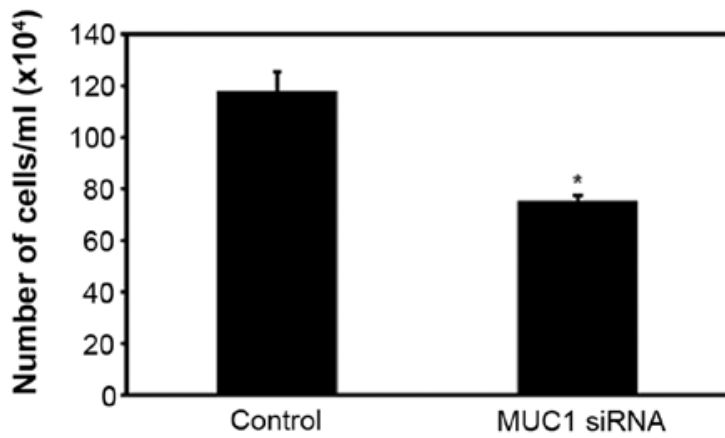

D

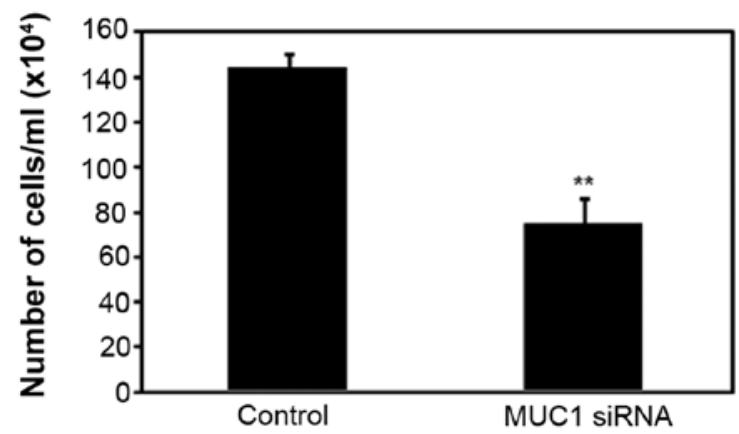

Figure 5. Knockdown of MUC1 reduces MRP1 expression and enhances the efficacy of doxorubicin. MCF-7 (A) and MDA-MB-231 (B) were transfected with control or MUC1 siRNA for $48 \mathrm{~h}$, protein extracted and expression level of MUC1, MRP1 was examined by immunoblotting with antibodies recognizing MUC1 and MRP1, respectively. $\beta$-tubulin was used as loading control. MCF-7 (C) and MDA-MB-231 (D) were transfected with control or MUC1 siRNA, treated with $1 \mu \mathrm{M}$ DOX for $48 \mathrm{~h}$ and live cells were counted using trypan blue. Data are mean of $\pm \mathrm{SE}(\mathrm{n}=3)$. $^{*} \mathrm{p}=0.04 \mathrm{versus}$ control; ${ }^{* *} \mathrm{p}=0.01$ versus control.

transfected cells. Knock-down of MUC1 protein in MCF-7 cells suppressed MRP1 protein expression in these cells (Fig. 5A). Similarly, in MDA-MB-231 cells, MRP1 protein expression was suppressed in MUC1 silenced cells (Fig. 5B). With direct evidence to corroborate the findings from Fig. 4, these results suggest that MUC1 directly regulates MRP1 in mammary carcinoma cells.

Since MUC1 regulates MRP1, we next assessed the growth and inhibitory effects of DOX in mammary carcinoma cells transfected with control and MUC1 siRNA using trypan blue. MCF-7 and MDA-MB-231 cells were transfected with control or MUC1 siRNA, treated with $1 \mu \mathrm{M}$ DOX for $48 \mathrm{~h}$ and cells were counted using trypan blue. The sensitivity to DOX in MUC1 siRNA transfected MCF-7 and MDA-MB-231 cells was significantly increased compared to the cells treated with the control siRNA (Fig. 5C and D). Taken together our results indicate that silencing MUC1 suppresses MRP1 which in turn enhances the efficacy of DOX-mediated growth suppression in mammary carcinoma cells.

\section{Discussion}

The role of MUC1 in promoting breast cancer development and its overexpression leading to mammary gland hyperplasia in mouse models is well established $(38,39)$. MUC1 is well known to induce chemoresistance in several cancer types (18-20). To understand the relationship between MUC1 and MRP1 in breast cancer cells, we examined the effect of honokiol on these two proteins, while gaining insights on the functional consequence of regulating these genes. This study shows that honokiol downregulates the expression of
MUC1 and MRP1 in breast cancer cell lines and increases the efficacy of DOX-mediated growth suppression. Silencing MUC1 gene expression in breast cancer cells reduces the expression of MRP1, and improves the potency of DOX to suppress cell growth. By examining the protein expression of MUC1 and MRP1 in honokiol-treated mammary carcinoma cells, we have observed that honokiol reduces MRP1 contingent upon the reduction of MUC1 expression. This report provides mechanistic data that regulation of MRP1 is dependent on MUC1 in mammary carcinoma cells, and combining honokiol with DOX reduces the toxic effects of this chemotherapeutic agent by modulating MUC1-mediated MRP1 expression.

Though MUC1 is well known for its metastatic properties, several mechanisms by which MUC1 confers chemoresistance have been reported and these mechanisms may be cancer type-specific or dependent on the chemotherapeutic agent. For instance, in breast, colon and thyroid cancer, MUC1 has been involved in blocking apoptosis induced by genotoxic or chemotherapeutic agents such as cisplatin by controlling the release of cytochrome $c(20,40,41)$. In pancreatic cancer cells, previous study demonstrated that overexpression of MUC1 decreases sensitivity to chemotherapeutic drugs by increasing the expression of MRP1 (18). MUC1 immmuotherapy, including antibodies, vaccines or inhibitors against MUC1, have long been sought as a target of investigation, however, none of these therapies for MUC1 are under clinical applications (42). In this study, natural product honokiol, which is not toxic to normal breast epithelial cells, suppresses MRP1 and MUC1 expression at both the mRNA and protein level, suggesting a novel therapeutic inhibitor to block both chemoresistance and cancer 
progression in breast cancer. However, it is beyond the scope of this study to determine how honokiol regulates MUC1 and future studies will be initiated to investigate this question.

Here, we provide evidence that honokiol-mediated downregulation of MRP1 is directed by suppression of MUC1. Thus, MUC1 regulates MRP1 in mammary carcinoma cells. Though new chemosensitizers and novel ways such as RNA interference and epigenetic regulation are emerging as targets to overcome MDR, honokiol may provide an alternative means to regulate drug resistance and metastasis by suppressing the expression of the two proteins involved in this phenomenon, MRP1 and MUC1, respectively. Although honokiol has been shown to suppress MDR gene product P-glycoprotein (43), this study focuses on the effect of honokiol on MRP1, which has been associated to shorter disease-free survival of breast cancer patients $(8,13)$. A significant correlation between high expression levels of MRP1 and response to treatment have been observed in breast tumors $(8,13)$. Having observed that honokiol suppresses MRP1 in triple-negative breast cancer cell line, MDA-MB-231 cells and estrogen receptor-positive mammary carcinoma cell line, $\mathrm{MCF}-7$ promotes further investigation of using honokiol, in combination with traditionally used chemotherapeutic agents in breast cancer.

To extend these observations in breast cancer cells, we evaluated the relationship between MUC1 and MRP1 in the mammary carcinoma cells MDA-MB-231 and MCF-7. We have shown that regulation of MRP1 is directly dependent on MUC1 expression in the estrogen receptor-positive and triple-negative breast cancer cell lines. This suggested that downregulation of MRP1 by MUC1 would likely sensitize mammary carcinoma cells to chemotherapeutic agents. In light of the mounting evidence that there is a correlation between MUC1 and MRP1, we explored the relationship between MUC1 and MRP1 in regulating resistance to chemotherapeutic agent, DOX, a substrate of MRP1. Accordingly, abrogation of MUC1 improved the responsiveness of mammary carcinoma cells to DOX. Interestingly, our data also showed that downregulation of MUC1 and MRP1 by honokiol enhances the efficacy of DOX-mediated growth suppression. We provide mechanistic evidence that downregulation of MUC1 by honokiol suppresses MRP1 which increases the potency of DOX.

Toxicity is an issue with chemotherapeutic drugs and limiting the dosage is a way to circumvent this problem. However, breast cancer patients may require higher dosages or may ultimately become resistant to chemotherapy. Along with existing drug treatments for breast cancer, the focus of clinicians and researchers have shifted towards exploring natural products. Various approaches to enhance chemoresponse in chemoresistant cancer models have been explored, including combining standard chemotherapy agents with natural products (44-46). Because of the toxicity associated with chemotherapeutic agents, combination with natural products that do not affect normal cells may improve the efficacy of chemotherapeutic drugs, while reducing the cardiac toxicity implicated with these agents. As shown in this study, the advantage of honokiol is that it does not affect normal breast cells and requires a high dose of honokiol $(>50 \mu \mathrm{M})$ to even have a growth inhibitory effect in normal breast cancer cells. Combining DOX with honokiol improves the efficacy of DOX-mediated growth suppression in mammary carcinoma cells. By reducing the dosage of DOX by combinatorial treatment with honokiol, toxicity associated with chemotherapeutic agents such as DOX can be reduced.

Mechanistically, we provide evidence that honokiol improves the efficacy of DOX by modulating the interplay between MUC1 and MRP1. The interaction of multiple proteins in cancer progression poses a therapeutic challenge in controlling and managing the disease. Combinatorial treatment of chemotherapeutic regimen with agents that target different mechanisms of action in cancer progression, such as drug resistance and metastasis are warranted, especially in reducing the toxicity of standard chemotherapeutic agents. Future studies will further dissect the mechanism by which honokiol regulates MUC1 and its translational effect in cancer transformation. Nevertheless, this study demonstrates that honokiol enhances the efficacy of DOX by intervening in the crosstalk between MUC1 and MRP1 in mammary carcinoma cells.

\section{Acknowledgements}

This study was supported by the start up funds from the College of Allied Health Professions at University of South Alabama. The authors would like to thank the Department of Pharmacology, University of South Alabama for use of their film developer.

\section{References}

1. Weigelt B, Peterse JL and van 't Veer LJ: Breast cancer metastasis: Markers and models. Nat Rev Cancer 5: 591-602, 2005.

2. Ripperger T, Gadzicki D, Meindl A and Schlegelberger B: Breast cancer susceptibility: Current knowledge and implications for genetic counselling. Eur J Hum Genet 17: 722-731, 2009.

3. McCubrey JA, Abrams SL, Fitzgerald TL, Cocco L, Martelli AM, Montalto G, Cervello M, Scalisi A, Candido S, Libra M, et al: Roles of signaling pathways in drug resistance, cancer initiating cells and cancer progression and metastasis. Adv Biol Regul 57: 75-101, 2015.

4. Kerbel RS, Kobayashi H and Graham CH: Intrinsic or acquired drug resistance and metastasis: Are they linked phenotypes? J Cell Biochem 56: 37-47, 1994.

5. Lønning PE: Molecular basis for therapy resistance. Mol Oncol 4: 284-300, 2010.

6. Munoz M, Henderson M, Haber M and Norris M: Role of the MRP1/ABCC1 multidrug transporter protein in cancer. IUBMB Life 59: 752-757, 2007.

7. Deeley RG, Westlake C and Cole SP: Transmembrane transport of endo- and xenobiotics by mammalian ATP-binding cassette multidrug resistance proteins. Physiol Rev 86: 849-899, 2006.

8. Nooter K, de la Riviere GB, Klijn J, Stoter G and Foekens J: Multidrug resistance protein in recurrent breast cancer. Lancet 349: 1885-1886, 1997.

9. Berger W, Setinek U, Hollaus P, Zidek T, Steiner E, Elbling L, Cantonati H, Attems J, Gsur A and Micksche M: Multidrug resistance markers P-glycoprotein, multidrug resistance protein 1, and lung resistance protein in non-small cell lung cancer: Prognostic implications. J Cancer Res Clin Oncol 131: 355-363, 2005.

10. Bagnoli M, Beretta GL, Gatti L, Pilotti S, Alberti P, Tarantino E, Barbareschi M, Canevari S, Mezzanzanica D and Perego P: Clinicopathological impact of $\mathrm{ABCC} 1 / \mathrm{MRP} 1$ and $\mathrm{ABCC} 4 /$ MRP4 in epithelial ovarian carcinoma. BioMed Res Int 2013: 143202,2013

11. Larbcharoensub N, Leopairat J, Sirachainan E, Narkwong L, Bhongmakapat T, Rasmeepaisarn K and Janvilisri T: Association between multidrug resistance-associated protein 1 and poor prognosis in patients with nasopharyngeal carcinoma treated with radiotherapy and concurrent chemotherapy. Hum Pathol 39: 837-845, 2008. 
12. Taheri M and Mahjoubi F: MRP1 but not MDR1 is associated with response to neoadjuvant chemotherapy in breast cancer patients. Dis Markers 34: 387-393, 2013.

13. Zöchbauer-Müller S, Filipits M, Rudas M, Brunner R, Krajnik G, Suchomel R, Schmid K and Pirker R: P-glycoprotein and MRP1 expression in axillary lymph node metastases of breast cancer patients. Anticancer Res 21 (1A): 119-124, 2001.

14. Kathawala RJ, Gupta P, Ashby CR Jr and Chen ZS: The modulation of $\mathrm{ABC}$ transporter-mediated multidrug resistance in cancer: A review of the past decade. Drug Resist Updat 18: 1-17, 2015.

15. Chatterjee K, Zhang J, Honbo N and Karliner JS: Doxorubicin cardiomyopathy. Cardiology 115: 155-162, 2010.

16. Kufe DW: Mucins in cancer: Function, prognosis and therapy. Nat Rev Cancer 9: 874-885, 2009.

17. Hollingsworth MA and Swanson BJ: Mucins in cancer: Protection and control of the cell surface. Nat Rev Cancer 4: 45-60, 2004

18. Nath S, Daneshvar K, Roy LD, Grover P, Kidiyoor A, Mosley L, Sahraei M and Mukherjee P: MUC1 induces drug resistance in pancreatic cancer cells via upregulation of multidrug resistance genes. Oncogenesis 2: e51, 2013.

19. Deng M, Jing DD and Meng XJ: Effect of MUC1 siRNA on drug resistance of gastric cancer cells to trastuzumab. Asian Pac J Cancer Prev 14: 127-131, 2013

20. Ren J, Agata N, Chen D, Li Y, Yu WH, Huang L, Raina D, Chen W, Kharbanda S and Kufe D: Human MUC1 carcinomaassociated protein confers resistance to genotoxic anticancer agents. Cancer Cell 5: 163-175, 2004.

21. El-Senduny FF, Badria FA, El-Waseef AM, Chauhan SC and Halaweish F: Approach for chemosensitization of cisplatinresistant ovarian cancer by cucurbitacin B. Tumour Biol: Aug 5, 2015 (Epub ahead of print).

22. Yiannakopoulou EC: Interaction of green tea catechins with breast cancer endocrine treatment: A systematic review. Pharmacology 94: 245-248, 2014.

23. Hu H, Zhang XX, Wang YY and Chen SZ: Honokiol inhibits arterial thrombosis through endothelial cell protection and stimulation of prostacyclin. Acta Pharmacol Sin 26: 1063-1068, 2005

24. Kim BH and Cho JY: Anti-inflammatory effect of honokiol is mediated by PI3K/Akt pathway suppression. Acta Pharmacol Sin 29: 113-122, 2008

25. Kumar A, Kumar Singh U and Chaudhary A: Honokiol analogs: A novel class of anticancer agents targeting cell signaling pathways and other bioactivities. Future Med Chem 5: 809-829, 2013.

26. Arora S, Singh S, Piazza GA, Contreras CM, Panyam J and Singh AP: Honokiol: A novel natural agent for cancer prevention and therapy. Curr Mol Med 12: 1244-1252, 2012.

27. Lee YJ, Lee YM, Lee CK, Jung JK, Han SB and Hong JT: Therapeutic applications of compounds in the Magnolia family. Pharmacol Ther 130: 157-176, 2011.

28. Wang L, Waltenberger B, Pferschy-Wenzig EM, Blunder M, Liu X, Malainer C, Blazevic T, Schwaiger S, Rollinger JM, Heiss EH, et al: Natural product agonists of peroxisome proliferator-activated receptor gamma (PPAR $\gamma$ ): A review. Biochem Pharmacol 92: 73-89, 2014.

29. Munroe ME, Arbiser JL and Bishop GA: Honokiol, a natural plant product, inhibits inflammatory signals and alleviates inflammatory arthritis. J Immunol 179: 753-763, 2007.

30. Chilampalli C, Zhang X, Kaushik RS, Young A, Zeman D, Hildreth MB, Fahmy H and Dwivedi C: Chemopreventive effects of combination of honokiol and magnolol with $\alpha$-santalol on skin cancer developments. Drug Discov Ther 7: 109-115, 2013.

31. Shigemura K, Arbiser JL, Sun SY, Zayzafoon M, Johnstone PA, Fujisawa M, Gotoh A, Weksler B, Zhau HE and Chung LW: Honokiol, a natural plant product, inhibits the bone metastatic growth of human prostate cancer cells. Cancer 109: 1279-1289, 2007.
32. Ishitsuka K, Hideshima T, Hamasaki M, Raje N, Kumar S, Hideshima H, Shiraishi N, Yasui H, Roccaro AM, Richardson P, et al: Honokiol overcomes conventional drug resistance in human multiple myeloma by induction of caspase-dependent and -independent apoptosis. Blood 106: 1794-1800, 2005.

33. Livak KJ and Schmittgen TD: Analysis of relative gene expression data using real-time quantitative PCR and the 2(-Delta Delta C(T)) method. Methods 25: 402-408, 2001.

34. Hu J, Chen LJ, Liu L, Chen X, Chen PL, Yang G, Hou WL, Tang MH, Zhang F, Wang XH, et al: Liposomal honokiol, a potent anti-angiogenesis agent, in combination with radiotherapy produces a synergistic antitumor efficacy without increasing toxicity. Exp Mol Med 40: 617-628, 2008.

35. Liu H, Zang C, Emde A, Planas-Silva MD, Rosche M, Kühnl A, Schulz CO, Elstner E, Possinger K and Eucker J: Anti-tumor effect of honokiol alone and in combination with other anticancer agents in breast cancer. Eur J Pharmacol 591: 43-51, 2008.

36. Park EJ, Min HY, Chung HJ, Hong JY, Kang YJ, Hung TM, Youn UJ, Kim YS, Bae K, Kang SS, et al: Down-regulation of c-Src/EGFR-mediated signaling activation is involved in the honokiol-induced cell cycle arrest and apoptosis in MDA-MB-231 human breast cancer cells. Cancer Lett 277: 133-140, 2009.

37. Hooijberg JH, Jansen G, Kathmann I, Pieters R, Laan AC, van Zantwijk I, Kaspers GJ and Peters GJ: Folates provoke cellular efflux and drug resistance of substrates of the multidrug resistance protein 1 (MRP1). Cancer Chemother Pharmacol 73: 911-917, 2014

38. Li Y, Liu D, Chen D, Kharbanda S and Kufe D: Human DF3/ MUC1 carcinoma-associated protein functions as an oncogene. Oncogene 22: 6107-6110, 2003.

39. Schroeder JA, Masri AA, Adriance MC, Tessier JC, Kotlarczyk KL, Thompson MC and Gendler SJ: MUC1 overexpression results in mammary gland tumorigenesis and prolonged alveolar differentiation. Oncogene 23: 5739-5747, 2004.

40. Raina D, Kharbanda S and Kufe D: The MUC1 oncoprotein activates the anti-apoptotic phosphoinositide 3-kinase/Akt and Bcl-xL pathways in rat 3Y1 fibroblasts. J Biol Chem 279: 20607-20612, 2004

41. Siragusa M, Zerilli M, Iovino F, Francipane MG, Lombardo Y, Ricci-Vitiani L, Di Gesù G, Todaro M, De Maria R and Stassi G: MUC1 oncoprotein promotes refractoriness to chemotherapy in thyroid cancer cells. Cancer Res 67: 5522-5530, 2007.

42. Rivalland G, Loveland B and Mitchell P: Update on Mucin-1 immunotherapy in cancer: A clinical perspective. Expert Opin Biol Ther 15: 1773-1787, 2015.

43. Xu D, Lu Q and $\mathrm{Hu}$ X: Down-regulation of P-glycoprotein expression in MDR breast cancer cell MCF-7/ADR by honokiol. Cancer Lett 243: 274-280, 2006.

44. Wang X, Beitler JJ, Wang H, Lee MJ, Huang W, Koenig L, Nannapaneni S, Amin AR, Bonner M, Shin HJ, et al: Honokiol enhances paclitaxel efficacy in multi-drug resistant human cancer model through the induction of apoptosis. PLoS One 9: e86369, 2014.

45. Arora S, Bhardwaj A, Srivastava SK, Singh S, McClellan S, Wang B and Singh AP: Honokiol arrests cell cycle, induces apoptosis, and potentiates the cytotoxic effect of gemcitabine in human pancreatic cancer cells. PLoS One 6: e21573, 2011.

46. Leeman-Neill RJ, Cai Q, Joyce SC, Thomas SM, Bhola NE, Neill DB, Arbiser JL and Grandis JR: Honokiol inhibits epidermal growth factor receptor signaling and enhances the antitumor effects of epidermal growth factor receptor inhibitors. Clin Cancer Res 16: 2571-2579, 2010. 